\title{
A MINIATURIZED MICROBIAL FUEL CELL
}

\author{
Mu Chiao, Kien B. Lam, Yu-Chuan Su and Liwei Lin \\ Berkeley Sensor and Actuator Center \\ Department of Mechanical Engineering, 1113 Etcheverry Hall \\ University of California at Berkeley, Berkeley, CA 94720-1740 \\ Email: muchiao@me.berkeley.edu Phone: 510-642-8983
}

\begin{abstract}
This paper presents a miniaturized microbial fuel cell as an energy source for MEMS. A microorganism, Saccharomyces cerevisiae, is used to catalyse glucose and electricity is produced by the overall redox reaction. The fabricated miniaturized microbial fuel cell has an electrode area of $0.07 \mathrm{~cm}^{2}$. The bio-electrical responses of the miniaturized microbial fuel cell are characterized. The open-circuit potential is measured as $300 \mathrm{mV}$ and lasts for 2 hours. The current density is measured as $286 \mathrm{nA} / \mathrm{cm}^{2}$ and lasts for $30 \mathrm{~min}$ utes under a $100 \mathrm{ohm}$ load.
\end{abstract}

\section{INTRODUCTION}

Miniaturized, portable power sources are important for the realization of MEMS. Previous approaches including micro turbine engines and micro batteries[1,2] have been proposed. In this paper, we have demonstrated the feasibility of a miniaturized microbial fuel cell as an energy source for MEMS.

Figure 1 shows the operation principle of a microbial fuel cell. In the anode compartment, microorganisms, such as Saccharomyces cerevisiae, are put into a buffer solution. Glucose is fed to the microorganisms and the hydrogen protons, electrons and carbon dioxide are generated during the fermentation process[3]. The electrons are transferred to the electrode and protons are diffused through a proton-exchange membrane(PEM). In order to increase the electron transfer efficiency, an electron transfer mediator is needed in the anolyte suspension[4]. In the cathode compartment, oxidizing materials such as potassium ferricyanide can be used to accept the electrons and reduce to ferrocyanide. The reduced ferrocyanide is oxidized by oxygen and returns to ferricyanide and water. The wastes produced in the microbial fuel cell are carbon dioxide and water.

\section{FABRICATION PROCESSES}

Figure 2(a) shows the close-up diagram of the PEM with $\mathrm{Cr} / \mathrm{Au}$ electrode. Filter papers with $0.2 \mu \mathrm{m}$ porosity are used as the electrode support and $\mathrm{Cr} / \mathrm{Au}$ is thermal evaporated on to the support. After the electrodes with porous supports are fabricated, they are thermal compression bonded to the PEM, Dupont Nafion-117. Figure 2(b) shows

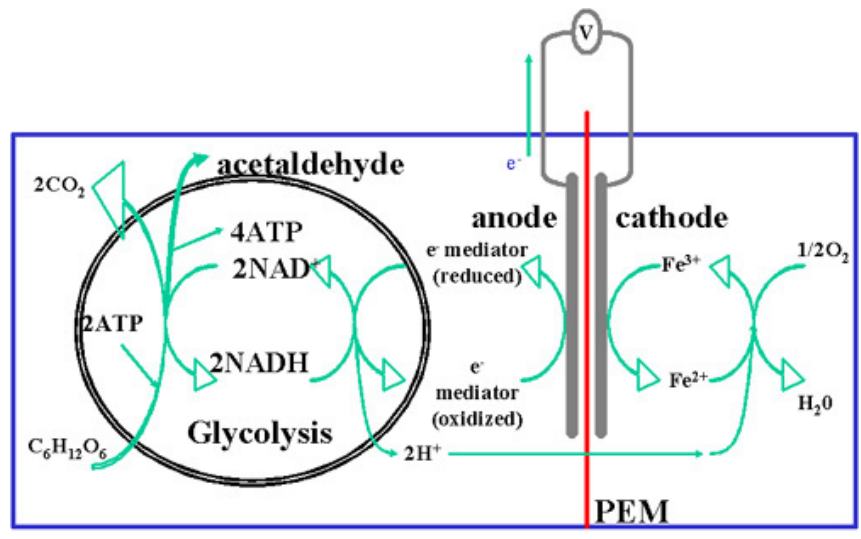

Figure 1: Operational principle of a microbial fuel cell.

the explode diagram of of the miniaturized microbial fuel cel. The electrode area is $0.07 \mathrm{~cm}^{2}$ and the fluid ports are made of plastic with o-ring seal to minimize leakage. In the final assembly step, the fluid ports and the electrode/PEM assembly are glued together and ready for testing.

\section{EXPERIMENTAL PROCEDURES AND RESULTS}

The anolyte is prepared as the following: microorganism culture (Saccharomyces cerevisiae) is mixed with glucose in a $0.1 \mathrm{M}$ phosphate buffer $(\mathrm{pH}$ 7.0). An electron transfer mediator, methylene blue of $0.01 \mathrm{M}$ is then added in to promote the bio-electrical reaction efficiency. Moreover, a sufficient aeration is provided to enhance the fermentation process. On the cathode side, a $0.02 \mathrm{M}$ potassium ferricyanide solution is prepared in a $0.1 \mathrm{M}$ phosphate buffer $(\mathrm{pH}$ 7.0). The bio-electrical responses are measured by dropping a drop(volume 0.16 c.c.) of each corresponding solutions into the anode and cathode compartments and the electrical signals are measured chronically. Figure 3 shows the measurement results of the open-circuit voltage response of a microbial fuel cell. The voltage goes up to $300 \mathrm{mV}$ and lasts for more than 2 hours. The final voltage drop after 2 hours is identified as solution dried out in air. The fuel cell discharge experiment is also carried out and the result is shown in Fig. 4 for two loading conditions. In the first loading condition, a bare conduction wire with resistance of $0.18 \mathrm{ohm}$ is used. As shown in Fig. 4, the voltage goes up 


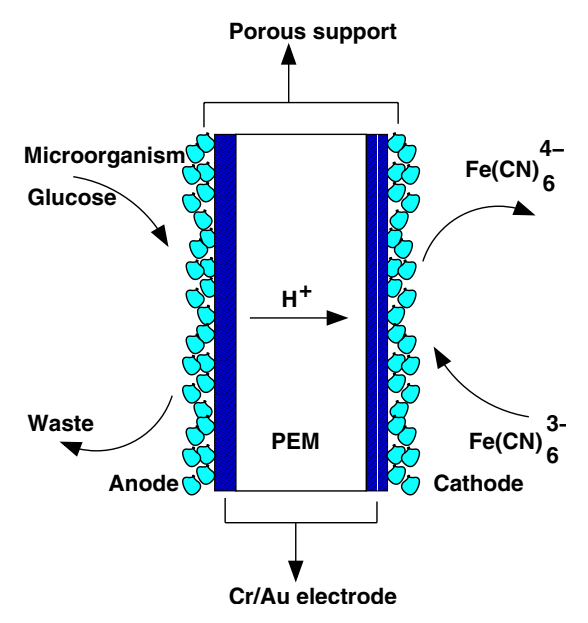

(a)

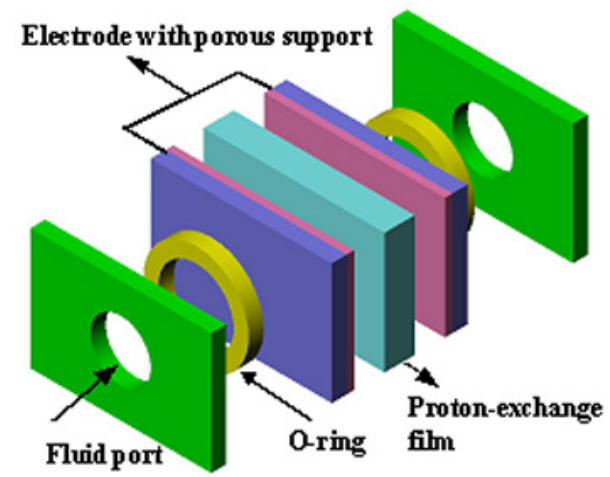

(b)

Figure 2: Design of a miniaturized microbial fuel cell. (a): A close-up schematic diagram of the PEM, $\mathrm{Cr} / \mathrm{Au}$ electrodes and porous support. (b): Final assembly of the fuel cell.

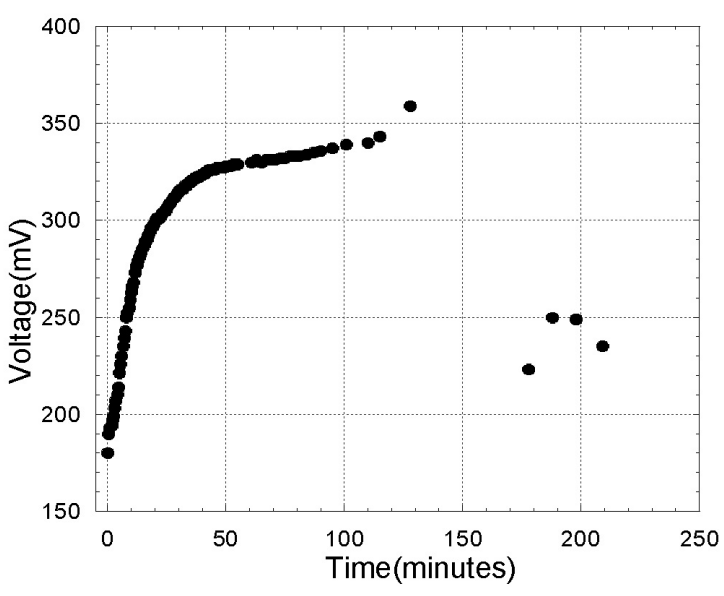

Figure 3: Open-circuit voltage measurement results. to $13 \mu \mathrm{V}$ in 10 minutes. In the second loading condition, a resistor of $100 \mathrm{ohm}$ is used, the voltage maintains at $2 \mu \mathrm{V}$ for 30 minutes. The current density of $286 \mathrm{nA} / \mathrm{cm}^{2}$ is then calculated by dividing the current with the electrode area.

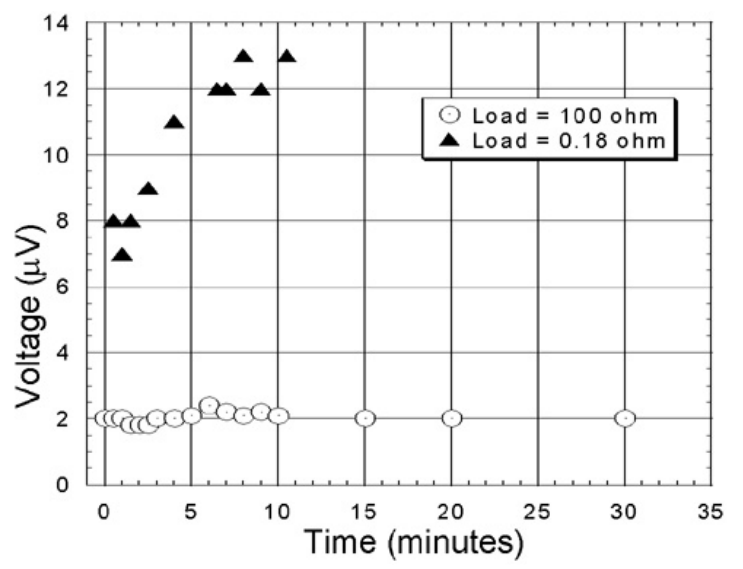

Figure 4: Microbial fuel cell discharge measurement results.

\section{CONCLUSIONS}

In this paper, we have demonstrated a miniaturized microbial fuel cell as a power source for MEMS. Saccharomyces cerevisiae is used to catalyse glucose and generate electricity. The wastes in the fuel cell are water and carbon dioxide. The fuel cell electrode area is $0.07 \mathrm{~cm}^{2}$ and the current density is measured as $286 \mathrm{nA} / \mathrm{cm}^{2}$ under $100 \mathrm{ohm}$ and remains stable for 30 minutes. The open-circuit voltage goes up to $300 \mathrm{mV}$ and lasts for 2 hours.

\section{ACKNOWLEDGEMENTS}

The authors would like to thank Mr. K.S. Teh and Ms. K. Cheung at UCB for valuable discussions on bacteria culturing. Theses devices are fabricated at the UCB Microfabrication Laboratory. This work is supported in part by an NSF CAREER award(ECS-0096098) and a DARPA MTO/MEMS grant (F30602-98-2-0227).

\section{REFERENCES}

[1] C. L. Tsai and A. K. Henning. Surface micromachined turbines. Proc. of 9th IEEE Int'l Conference on Solid-State Sensors and Actuators, pages 829-832, 1997.

[2] K. B. Lee and L. Lin. Electrolyte based on-demand and disposable microbattery. In Technical Digest of IEEE Micro Electro Mechanical Systems, pages 236-239, Jan 2002.

[3] H. A. Videla and A. J. Arvia. The responses of a bioelectrochemical cell with saccharomyces cerevisiae metabolizing glucose under various fermentation conditions. Biotechnology and bioengineering, XVII:1529-1543, 1975.

[4] T. Akiba, H. P. Bennetto, J. L. Stirling, and K. Tanaka. Electricity production from alkalophilic organisms. Biotechnology Letters, 9:611-616, 1987. 